\title{
Evolution
}

\section{Early tetrapods had an eye on the land}

\author{
Nadia B. Fröbisch \& Florian Witzmann
}

Fossil finds that can provide clues about how aquatic vertebrates evolved into land dwellers are elusive. But the ancient bones of a newly discovered species of tetrapod now provide some crucial missing evidence. See p.527

Following the scientific investigations into how vertebrates transitioned from water to land is like reading a good crime novel. We have a range of suspects, patchy evidence and a lot of unanswered questions. And to complicate matters, this transition from finned fish to four-limbed creatures (tetrapods) is a 'cold case' from nearly 400 million years ago. On page 527 , Beznosov et al. ${ }^{1}$ present some compelling detective work that sheds light on this.

The earliest-known tetrapod specimens are 380-million-year-old bone fragments that, although identifiable as belonging to a tetrapod, do not provide many details about what these animals looked like or how they lived $^{2}$. There are also fossilized tetrapod footprints that pre-date these fossil finds by more than 14 million years ${ }^{3}$, indicating the presence of a four-limbed, still fully aquatic track maker - but they do not reveal what the track maker looked like above the soles of its feet.

More-detailed insights into the body shape, life and growth of our early vertebrate ancestors are provided by more-complete fossil finds, including the iconic tetrapods Acanthostega and Ichthyostega ${ }^{2,4}$. However, these lived 365 million years ago, when tetrapods had already achieved an impressive geographical distribution and a diverse variety

\section{"This water dweller was looking above the surface of the water."}

\section{of body shapes and ways of life ${ }^{2}$.}

By contrast, the earliest phase of tetrapod evolution and diversification has long been mysterious. However, Beznosov and colleagues now describe skeletal fossils of a species they call Parmastega aelidae, which is the most ancestral (basal-most) tetrapod reported so far.

Like its known younger relatives, $P$. aelidae was a gill-breathing water dweller, and the authors estimate that this animal reached a size of more than one metre long. It lived about 372 million years ago during the Devonian period, and inhabited a shallow lagoon in a landmass that is now part of northwestern Russia. These excellently preserved fossils provide crucial data about how the major changes in breathing, sensory perception, locomotion and feeding might have taken place as tetrapods transitioned to life on land. The discovery also raises many exciting questions.

The most striking features of the P. aelidae skull are the large, oval-shaped eye openings, which face to the front and side, and which are positioned high up, towards the top of the skull (Fig. 1). This eye shape and position is surprising because it indicates that this water dweller was looking above the surface of the water.

Mudskippers (species from the family Oxudercidae) are modern amphibious fish that inhabit marine mud flats, and they are useful living creatures with which to compare $P$. aelidae because their eyes have a similar shape and position. Mudskippers peek above the water surface to look out for prey and potential danger ${ }^{5}$. But what was P. aelidae looking for? The need to detect enemies on land or in the air can be ruled out, because during the late Devonian period, such animals were not yet present there.

One possibility is that $P$. aelidae was looking for prey on the shore. If so, what kind of terrestrial or semi-terrestrial prey was it watching? Some have suggested that early water-dwelling tetrapods and their closest fish-like relatives might have preyed on terrestrial invertebrates of the phylum Arthropoda, which includes insects ${ }^{6}$. However, the large arthropods that could have provided sufficient food to sustain an animal the size of $P$. aelidae were still rare

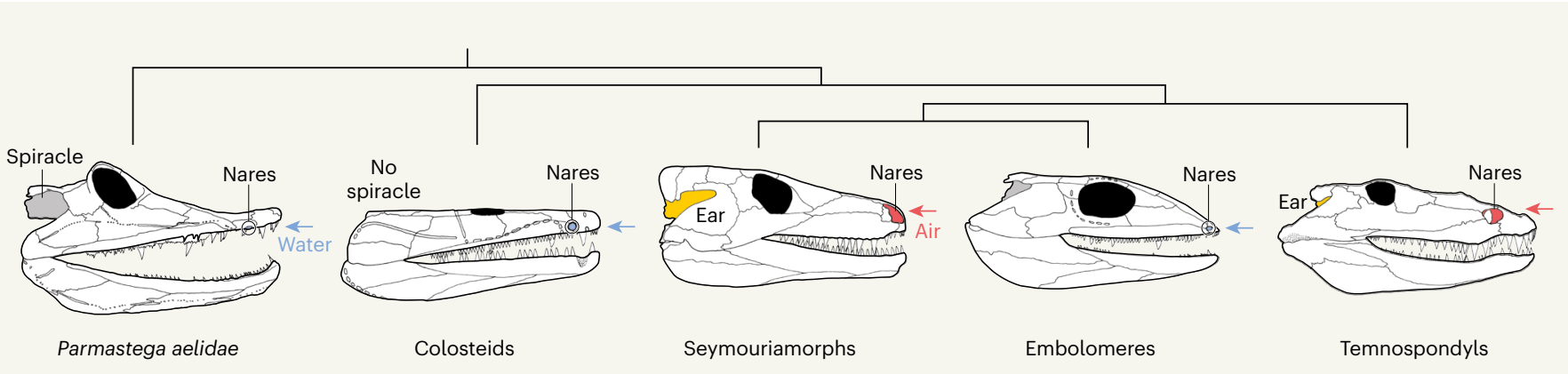

Figure 1 | The evolution of tetrapod skulls. Beznosov et al. ${ }^{1}$ report 372 -millionyear-old fossils of a four-limbed vertebrate (tetrapod) from just before the time when tetrapods moved onto land. They call this newly discovered species Parmastega aelidae. Its nasal passages (nares) are close to its jaw and would have been positioned under water. Water passing though the nares (blue arrow) would have been used for breathing when it reached the gills (not shown). P. aelidae could also breathe air directly through a skull opening called a spiracle (grey). Comparing these ancestral features of $P$. aelidae with other tetrapods reveals patterns of evolutionary change. The other tetrapods shown are: an early tetrapod group called colosteids; seymouriamorphs and embolomeres, members of a lineage that gave rise to amniotes (birds, reptiles and mammals); and temnospondyls, which gave rise to modern amphibians (such as frogs and salamanders). Colosteids lacked spiracles and breathed solely through their gills using water taken up through the nares. Compared with P. aelidae, seymouriamorphs and temnospondyls had larger and higher nares, which they would have used to breathe air (red arrow). These tetrapods lacked spiracles, and had ears (yellow) instead in that area of their skull. Embolomeres retained the breathing system used by $P$. aelidae. 
in the Devonian period ${ }^{7}$. Moreover, P. aelidae had large fangs, which suggests that it preyed mainly on vertebrates. Perhaps it searched for fish carcasses stranded on the shore. Or, to make an even more speculative suggestion, maybe it scavenged early amphibious tetrapods that rested near the water. However, evidence for such creatures has not yet been found among the fossils of the Sosnogorsk Formation (the rock layers that contained the P. aelidae fossil).

Another notable feature of $P$. aelidae is the extremely low position, close to its jaws, of the external openings of its nose (the nares), which would have been under water (Fig. 1). This is in striking contrast to the high position of its eyes and is quite different from the configuration of nares in modern-day aquatic tetrapod animals, such as crocodiles, hippopotamuses or frogs. The eyes of those animals sit on top of their head, and their nares are likewise positioned high on the snout, which enables them to breathe air while looking above water. Judging from their submerged position, P. aelidae nares acted as openings through which an inflow of water was directed towards the gills during breathing. P. aelidae also had the option of breathing air through a large opening in its skull called a spiracle (Fig. 1), and such a breathing process would probably have been similar to that used by modern air-breathing fish ${ }^{8}$.

This low position of the nares is found in most known early tetrapods (called stem tetrapods) of the Devonian period (approximately 419.2 million to 358.9 million years ago) and Carboniferous period (358.9 million to 298.9 million years ago). In all of these animals, the passage from the nares to the mouth cavity might still have served to transport water rather than air. Some fossils of stem tetrapods, such as those of a grouping called colosteids (Fig. 1), had lost their spiracle opening - they must therefore have relied on gill breathing. In some other early tetrapods that arose later than P. aelidae and were more evolved than their ancestors (a state described as being more derived), the spiracle is absent, and its place is taken by an ear ${ }^{2}$. These tetrapods' nares are larger and higher on the snout (Fig.1) compared with the ancestral form, suggesting that they used their nares to transport air towards the lungs while peeking out of the water when on the lookout for prey.

The $P$. aelidae fossils offer a treasure trove of information that could help to disentangle some of the complex evolutionary changes that took place when vertebrates made the transition from aquatic to terrestrial life. This discovery also reminds us that much still remains to be learnt in the next gripping chapter of this detective story.
Nadia B. Fröbisch and Florian Witzmann

are at the Natural History Museum, Leibniz Institute for Evolution and Biodiversity Science, 10115 Berlin, Germany. e-mails: nadia.froebisch@mfn.berlin; florian.witzmann@mfn.berlin

Beznosov, P. A., Clack, J. A., Lukševičs, E., Ruta, M. \& Ahlberg, P. E. Nature 574, 527-531 (2019).

2. Clack, J. A. Gaining Ground: The Origin and Evolution of Tetrapods 2nd edn (Indiana Univ. Press, 2012).

3. Niedźwiedzki, G., Szrek, P., Narkiewicz, K., Narkiewicz, M. \& Ahlberg, P. E. Nature 463, 43-48 (2010).

4. Sanchez, S., Tafforeau, P., Clack, J. A. \& Ahlberg, P. E. Nature 537, 408-411 (2016).

5. Schultze, H.-P. Sber Ges. Naturf. Freunde Berl. 36, 59-77 (1997)

6. Maclver, M. A., Schmitz, L., Mugan, U., Murphey, T. D. \& Mobley, C. D. Proc. Natl Acad. Sci. USA 114, E2375-E2384 (2017)

7. Shear, W. A. \& Kukalová-Peck, J. Can. J. Zool. 68, 1807-1834 (1990)

8. Graham, J. B. et al. Nature Commun. 5, 3022 (2014).

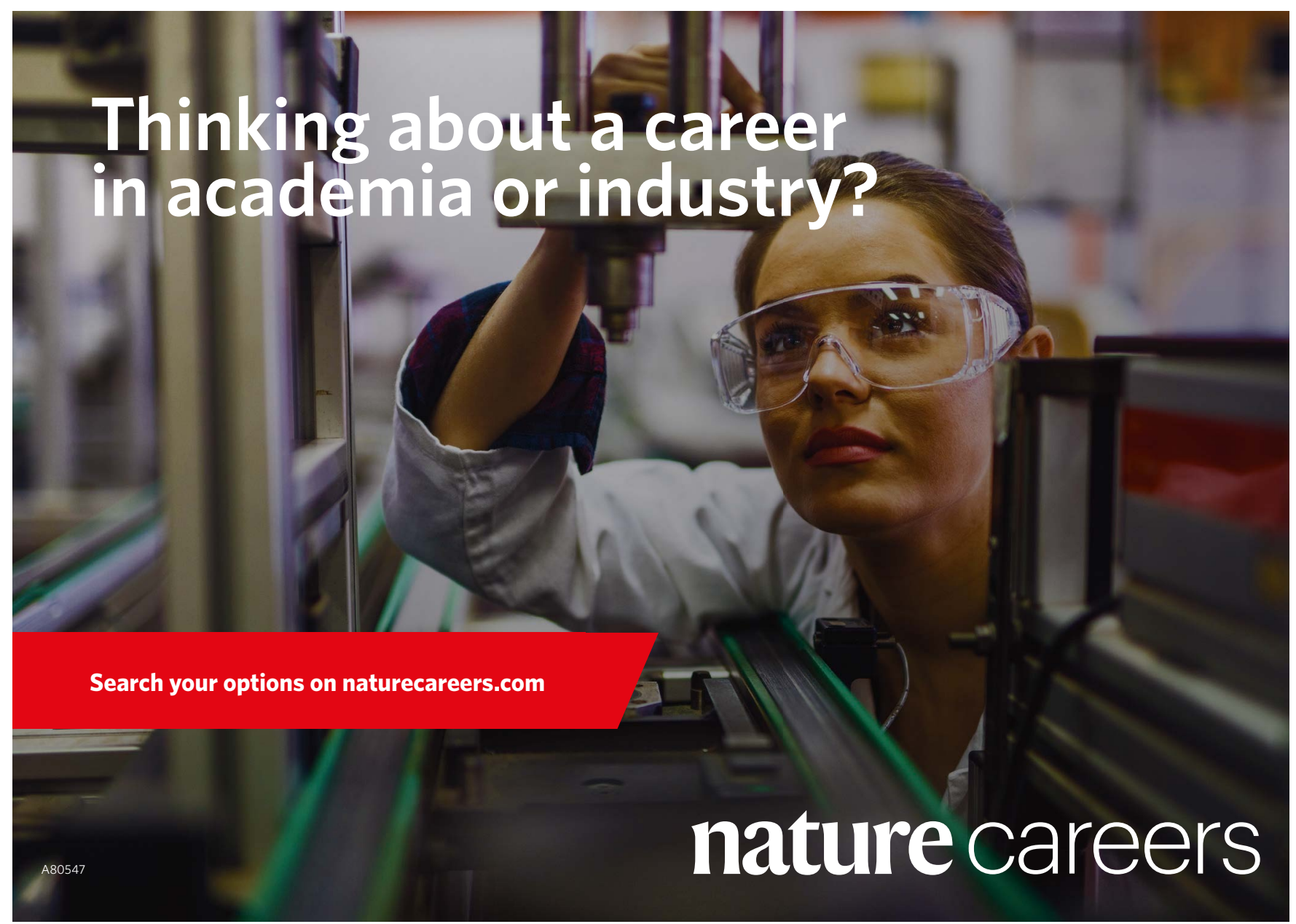

